\title{
IMAGENS, NARRATIVAS E CURRÍCULOS
}

\section{Apresentação}

O dossiê Imagens, narrativas e currículos inscreve-se em uma rede de pesquisa e possibilita diversas reflexões, cujo produto resultante viria a ser algo múltiplo. Admitimos este fato, há muito tempo, já que entendemos - ao contrário do que nos ensinaram a maioria dos movimentos de pensamento acerca de escolas ${ }^{1}$ - existir uma intensa relação entre os muitos "dentrofora"2 das escolas, possibilitada pelos movimentos cotidianos que os "praticantes-

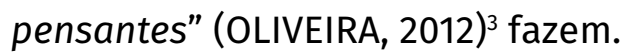

Trabalhando com a ideia de que todos nós formamos inúmeras redes educativas - todas de "práticasteorias" múltiplos "conhecimentossignificações" que

1 Lembremos: as diversas correntes da chamada Escola Nova observavam que era preciso que os fatos da sociedade entrassem na escola e que isto não acontecia. Estas perspectivas continuam hegemônicas hoje, em Educação. Falava-se, então (início do século XX) e fala-se ainda nos "muros das escolas", que impedem este movimento, esquecendo-se que todos os dias os estudantes e os docentes - e muitos outros - entram e saem das escolas carregando tudo o que "aprendemensinam" nas múltiplas redes educativas em que estão inseridos.

2 Buscando compreender os limites que as dicotomias - criadas por necessidade pelas ciências na Modernidade - traziam às pesquisas com os cotidianos que realizávamos, passamos a grafá-las desta maneira: com os termos reunidos, em itálico e com aspas simples. Isto nos permite perceber nossos próprios limites de formação e buscar ir além deles.

3 OLIVEIRA, Inês Barbosa de. Currículos e pesquisas com os cotidianos: o caráter emancipatório dos currículos "pensadospraticados" pelos "praticantespensantes" dos cotidianos das escolas. In: FERRAÇO, Carlos Eduardo: CARVALHO, Janete Magalhães (Orgs.). Currículos, pesquisas, conhecimentos e produção de subjetividades. Petrópolis, RJ: DP et Alli, 2012. p. 47-70.

4 Até o presente, identificamos e trabalhamos com as seguintes redes educativas: a das "práticasteorias" da formação acadêmica; a das "práticasteorias" pedagógicas cotidianas; a das "práticasteorias" das políticas de governo; a das "práticasteorias" coletivas dos movimentos sociais; a das "práticasteorias" de uso e fruição das artes; a das "práticasteorias" das pesquisas em educação; a das "práticasteorias" de produção e "usos" de mídias; e a das "práticasteorias" de vivências nas cidades, no campo e à beira das estradas. nelas são criados, são relacionados e referidos a todos os "espaçostempos" dessas mesmas, pelas tantas "idasvindas" que fazemos entre elas.

Nos "espaçostempos" escolares, assim, estão presentes inúmeros currículos ocupados por inúmeros "artefatos culturais" que se transformam em curriculares, com os processos pedagógicos aí desenvolvidos. Nestes encontramos: artefatos materiais - cadeiras, mesas, lousas, calendários, chamadas, janela climática, quadros diversos; produções externas de normatização, como leis de ensino, normas administrativas ou decisões da equipe de direção das regionais de ensino; crenças pedagógicas - teorias didáticas e curriculares, métodos de ensino, formas de trabalhar e estudar; artefatos tecnológicos - televisão, vídeos, instrumentos musicais etc. Aí estão também os corpos e as mentes daqueles que "habitam" esses "espaçostempos", fazendo-os seus: estudantes, docentes, pessoal administrativo e funcional, responsáveis pelos estudantes, comunidade local etc. O conjunto desses artefatos materiais, ideológicos e teóricos, somado aos seres humanos que os reproduzem e produzem outros "conhecimentossignificações" com eles, e que circulam diferentemente nos processos pedagógicos em cada escola, formam aquilo que chamamos de "currículos". Esses "espaçostempos" são, desse modo, com tudo o que neles circula, artefatos curriculares, também. Todo este conjunto de seres humanos, produtos e criações das relações de uns com os outros, adquire significados múltiplos e complexos nos processos educativos, exatamente porque seus diferentes "usos", na repetição, permitem que apareçam diferentes 
tecnologias de uso e a criação de "conhecimentossignificações" diversos.

Trançados esses processos, de modo crescente, as imagens, os sons e as narrativas habitam nossos mundos contemporâneos, nos tantos "dentrofora" das escolas. Na compreensão de que vivemos todos nas redes educativas múltiplas que formamos e nas quais nos formamos, podemos entender a importância que têm esses modos de "fazerpensar" o mundo, compartilhar a cotidianidade e produzir o presente nos tantos "dentrofora" das escolas e suas contribuições aos processos curriculares - sejam em conteúdos ou formas.

Nessas redes, os inúmeros artefatos culturais - de ideologias a metodologias, passando por conteúdos; do desenho ao cinema, passando pela fotografia; da televisão aos computadores, passando por celulares -, permitindo inúmeras e complexas relações entre os "praticantespensantes" das redes educativas, coengrendram e transformam, permanentemente, os processos de atribuir sentidos e tecer "conhecimentossignificações" que enriquecem nossos modos de "verouvir" e produzir - por nossos modos diferentes e contraditórios - a sociedade e a natureza, em sua complexidade e variedade.

Esses movimentos geram memórias e impulsionam a invenção de possiveis imagens e narrativas de escolas e de outras redes educativas, em todos os que nelas circulam, estabelecendo relações entre si e forjando, por sua vez, modos diferentes e complexos de "praticarpensar" os processos pedagógicos. Essas imagens, sons e narrativas, têm permitido o surgimento de inúmeras pesquisas que articulam diferentemente memórias, tecnologias e processos curriculares.

Esse dossiê, em sua diversidade de modos de usar e pensar imagens, narrativas e currículos, permitirá que pensemos nessas questões um pouco mais.
No primeiro texto do dossiê, Imagens dos corpos inscritas nas narrativas de alunos do ensino médio: as (inter)corporeidades e o currículo, Roberta Jardim Coube e Eda Maria de Oliveira Henriques, a partir de uma perspectiva de abordagem bakhtiniana, propõem-se a exercitar outros/novos modos de sentir, pensar e realizar a pesquisa em Educação. As autoras trouxeram para a problematização narrativas de si realizadas por alunos do ensino médio de um colégio federal do Rio de Janeiro sobre suas experiências nas aulas de Educação Física. Coube e Henriques indicam que as narrativas de si são potentes por exortarem uma pedagogia da escuta e por evidenciarem a importância de se estabelecer uma relação entre (inter)corporeidades e currículo escolar.

Aldo Victorio Filho e Rodrigo Torres do Nascimento abordam, em Práticas da imagem $e$ produção de vidas: insurgências curriculares visuais, estéticas e culturais nas redes, aspectos teóricos da imagem e sua relevância na formação de indivíduos e coletivos. Os autores, apoiados em dois ídolos juvenis - Inês Brasil e o grupo de funk Bonde das Bonecas - refletem sobre imagens caras a parte da juventude brasileira, nas redes sociais, e sobre processos de afirmação identitária como um de seus efeitos. 0 texto sugere que tais imagens, detentoras de contraestética e insurgência contra padrões imagéticos dominantes, instituem uma militância visual, engendrando modos de ser e de aprender a ser que desafiam a educação escolar face às produções curriculares confrontadas e contaminadas pelas redes e visualidades contemporâneas.

No texto Selfie e a tessitura de imagens $e$ currículos individuaiscoletivos com as redes educativas, Maria da Conceição Silva Soares, Vanessa Maia Barbosa de Paiva e João Barreto da Fonseca argumentam que esse campo especial de imagens, mais do que um registro fotográfico de si próprio, caracteriza-se pela 
busca de autoapresentação e conexão com o outro em redes sociais digitais. Os autores apontam que a produção e a distribuição de selfies provocam novas configurações éticas e estéticas, marcadas por uma forte exposição de si, inserindo o corpo no processo de comunicação. Sugerem ainda que a prática de selfies é complexa, por ser fruto de modelizações, de memórias, de retóricas e de maneiras de narrar e constituir currículos individuaiscoletivos, em processos de permanente criação de si e de mundos.

Evanilson Gurgel e Marlécio Maknamara, em "Minha vida daria um filme?" - uma viagem entre as fronteiras da realidade e da ficção, buscam identificar e diluir fronteiras entre essas duas perspectivas para pensar e classificar as narrativas do vivido. Para isso, traçam uma discussão sobre o lugar cativo das histórias de vida, o dispositivo da memória e a biografemática. No caminho de pensamento que Gurgel e Maknamara construíram, a linguagem cinematográfica do diretor cearense Karim Aïnouz emerge como possibilidade imagética e como conexão entre o real e o ficcional. 0 texto é intercalado por diários de bordo de Major Tom, personagem criado através do "fusão" dos autores, e traz alguns relatos autobiográficos concatenados ao que é discutido, transubstanciando, dessa forma, o rotineiro em fantástico.

Em Identity, identification and differentiation in contemporary brazilian comedies, Antonio Carlos Rodrigues de Amorim e David Martin-Jones analisam as maneiras pelas quais a identidade nacional é negociada em duas comédias brasileiras: Se Eu Fosse Você (2006) e Se Eu Fosse Você 2 (2009). De acordo com os autores, os filmes oferecem possibilidades para reimaginar identidades nacionais contra a corrente de uma padronização de imagemmovimento propagada por cinemas comerciais que operam reafirmando uma imagem normativa, homogênea, de classe média, nucleada pela família e classista. 0 artigo aponta o valor potencial da análise de tais filmes para pensar como as identidades culturais são construídas, assinalando que essas compreensões podem contribuir para o desenvolvimento de estudos curriculares.

André Luiz Bernardo Storino e Ivan Amaro, em Desenho animado, gênero e sexualidades: "A hora da aventura" $e$ as narrativas dissidentes na escola, argumentam em favor das possibilidades presentes neste artefato cultural para pensar as representações de gênero e sexualidade, a partir de narrativas de alunos e alunas do ensino médio de uma escola localizada na Baixada Fluminense, configurando significados que podem indicar subversões acerca dos conhecimentos que perpassam tais temáticas. No texto, as identidades de gênero e as orientações sexuais são tomadas em perspectiva não heterossexual, ao problematizar as representações de corpos e práticas que fogem à norma e desestabilizam as noções do suposto universo masculino e feminino, provocando novos saberes.

Em Que histórias os memes podem nos contar? Pedagogias culturais e currículo, Clícia Coelho toma as pedagogias culturais como possibilidade de materialização dos processos de ensino e aprendizagem, em conformidade com as concepções pós-críticas de currículo. Para a autora, esse pensamento requer concepções de conhecimento que impliquem a ampliação de enfoques para além dos contextos vinculados estritamente às instituições educativas, discutindo essas práticas a partir das insurgências culturais. 0 texto indica a emergência do "meme", como um tipo de narrativa visual que se tornou fenômeno da/ na internet, como dispositivo capaz de acionar memórias e provocar outros olhares sobre o trânsito/fluxo entre imagens, cotidiano, pedagogias e currículos, nas contingências da contemporaneidade. 
Em Currículo, conhecimentos e mídias: táticas $e$ invenções dos sujeitos nos cotidianos do Ensino Médio, Edivan Carneiro de Almeida e Elenise Cristina Pires de Andrade buscam estabelecer diálogos sobre as práticas dos sujeitos nos cotidianos escolares, a partir de resultados de uma pesquisa de mestrado, com experiências vividas-narradas por estudantes, no Projeto Comunicação, Interação e Aprendizagem, desenvolvido numa escola pública do sertão baiano. Os autores defendem que as experiências narradas, por meio de vídeos, configuram oportunidades para a construção de conhecimentos e de usos-apropriações de gêneros textuais, artefatos e mídias-linguagens, através da produção de imagens, informações e textos veiculados nos cotidianos da escola e na comunidade externa, através da rádio-escola, do blog e do boletim impresso, provocando uma fissura no currículo oficial-enrijecido - prescritivo e potencializando a criação de um currículo singular.

Sandra Nazaré Dias Bastos e Sílvia Nogueira Chaves discutem, no texto Entre raízes aéreas e exoesqueletos: a produção de currículos de biologia, possibilidades para a invenção de um currículo para a disciplina que, para além das prescrições e da dependência de equipamentos específicos, privilegie e fomente um olhar diferenciado sobre a natureza, por meio de procedimentos práticos e experimentais. As autoras sustentam que, se por um lado, é possivel entender o currículo como um conjunto de ordenamentos e de linhas fixas, por outro lado, é possível e desejável ver e exercitar possibilidades de rompimento que possibilitem a abertura para outras sensibilidades e (bio)lógicas.

No último texto Foto (e) grafias na formação de professores/as de educação física, Admir Soares de Almeida Junior reflete sobre o lugar ocupado pelas narrativas (visuais, orais e escritas), no processo de formação inicial e continuada de docentes para esse componente curricular. Para tanto, destaca algumas experiências desenvolvidas no âmbito da formação de docentes de Educação Física que tomam as imagens fotográficas e as narrativas como elementos estruturantes. Com esse trabalho, Admir Soares de Almeida Junior propõe que a produção de diferentes tipos de narrativas tem se configurado como uma relevante estratégia de formação.

Feito esse breve mapeamento do dossiê, convidamos os leitores a viajarem, ao modo das cartografias, por/entre/com as imagens e as narrativas criadas/trazidas pelos autores, tendo em vista pensar outras composições curriculares possiveis.

Rio de Janeiro, dezembro 2017

Maria da Conceição Silva Soares Nilda Alves

Programa de Pós-graduação em Educação Universidade do Estado do Rio de Janeiro 